\title{
Quantification of Toxic Elements in Tail Hair of Cows as an Indicator of Environmental Exposure in Different Areas from Iran
}

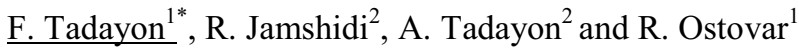 \\ ${ }^{1}$ Department of Chemistry, North Tehran Branch, Islamic Azad University, Tehran, Iran; F_Tadayon@iau-tnb.ac.ir \\ ${ }^{2}$ Department of Biochemistry, Faculty of Veterinary Medicine, Semnan University, Semnan, Iran
}

\begin{abstract}
This paper describes a new comparison and determination for demonstrating the levels of $\mathrm{Al}, \mathrm{Cd}$ and $\mathrm{Pb}$ in cow's tail hair between Tehran as a polluted area and Semnan as an area free from pollution. The hair samples were collected from a total 227 apparently healthy lactating cows above 3 years of age. This includes 165 cows reared in industrial and urban area (Tehran) and 62 cows reared in area supposed to be free from pollution (Semnan). Prior to analysis, samples were washed with $0.1 \mathrm{M} \mathrm{HCl}$, acetone and deionized water. The hair samples were digested afterward in a mixture of nitric and perchloric acid mixture $(\mathrm{HNO} 3: \mathrm{HCLO} 4=4: 1 \mathrm{v} / \mathrm{v})$. Concentrations of all metals were assessed by flame and graphite furnace atomic absorption spectrophotometer.
\end{abstract}

Key words: Toxic Elements, Tail hair, Cow, Environmental exposure

\section{Introduction}

The levels of trace elements are an important to increasing environmental pollution and it can result in various deleterious health effects in human and other animals. Lead and cadmium are the two most abundant heavy metals in the environment, often coexist in a polluted environment [1] and are mostly implicated in human and animal poisoning [2]. The common sources of lead and cadmium are diverse in nature including natural and anthropogenic processes such as combustion of coal and mineral oil, smelters, mining, alloy processing units, paint industries, etc.[3]. A variety of exposure routes allow toxic heavy metals predominantly lead and cadmium to enter the food chain of farm animals [4], Chronic exposure to these sulfhydryl reactive metals through various routes results in their higher accumulation in tissues, bones, hair and blood, and monitoring of these toxic metals in biological materials essentially indicates the status of environmental degradation [5-7].

Hair fiber is a metabolically dead material after it leaves the epidermis. However, the fiber in the root during its growth is metabolically very active. This is mainly because of the certain advantages offered by hair over other clinical specimens such as blood or urine, namely; (i) the concentrations of most trace elements are higher in hair than other clinical specimens; (ii) the stability of hair, as a biological material, which facilitates the storage and transport processes; (iii) unlike other clinical samples, hair is inert and chemically homogeneous, and (iv) trace elements present in the body are incorporated into the hair during its growth[8-10]. Hair samples have been used for noninvasive diagnosis of cadmium toxicity in humans [11]. The frequency of diseases such as autism has been predicted in humans using data on hair concentrations of cadmium and other minerals [12].Therefore it is hypothesized that increasing hair trace element levels in cows around industrial area, may influence the concentration of trace elements in milk.

In Iran, metal pollution is more than other countries so the status of toxic elements in food and drinking water in Iran is more than any other country. It triggers a lot of investigation. The main goal of this study was to evaluate the use of tail hair as a biomarker of lead, cadmium and aluminum, contents in cows above 3 years of age. The obtained concentration values of tail hair samples of Tehran as a polluted area were compared with Semnan as an area free from pollution. Quantification was performed by flame and electro thermal atomic absorption spectrometry (FAAS and ETAAS). 


\section{Methods and Materials}

\section{Sample Collection}

During 20010 - 2011, respective tail hair samples were collected from a total of 227 lactating cows of above 3 years of age reared in either around different industrial area from Tehran $(n=165)$ and in non-polluted of Semnan province $(n=62)$. Hair samples were taken from the tail switch using a scalpel and stored individually in sealed plastic bags at room temperature.

\section{Instrumentation}

A Varian model Spectra AA-220 (Mulgrava, Victoria, Australia), atomic absorption spectrometer equipped with a GTA-100 graphite furnace atomizer and deuterium lamp background correction was used with hollow cathode lamps (Varian). The spectrometer parameters are shown in Table 1.

Table 1. Spectrometer operating conditions and techniques.

\begin{tabular}{|c|c|c|c|}
\hline Elements & $\begin{array}{c}\text { Wavelength } \\
(\mathbf{n m})\end{array}$ & $\begin{array}{c}\text { Spectral } \\
\text { bandwidth } \\
(\mathbf{n m})\end{array}$ & $\begin{array}{c}\text { Lamp current } \\
(\mathbf{m A})\end{array}$ \\
\hline $\mathbf{C d}$ & 228.8 & 0.5 & 4.0 \\
\hline $\mathbf{A l}$ & 309.3 & 0.5 & 10 \\
\hline $\mathbf{P b}$ & 217.0 & 1.0 & 5.0 \\
\hline
\end{tabular}

\section{Reagents and Standard Solutions}

Suprapure Merck $\mathrm{HNO}_{3}$ and $\mathrm{HClO}_{4}$ was used in the treatment of tail hair samples and preparation of standard solutions. All reagents used in the present study were of analytical grade obtained from E. Merck. Deionized water of high purity (from a Millipore ultra-pure water system) was used. $\mathrm{Cd}, \mathrm{Al}$ and $\mathrm{Pb}$ stock standard solutions at a concentration of $1.000 \mathrm{~g}$. $\mathrm{L}^{-1}$ was prepared from, cadmium nitrate 4-hydrate, aluminum nitrate 9-hydrate and metal strip respectively (Merck).

Glassware, nalgene bottles and sealed plastic bags were all cleaned in $5 \%(\mathrm{v} / \mathrm{v})$ nitric acid before use.

\section{Washing Procedures}

The risk of sample contamination during the sampling and digestion was minimized. Prior to analysis, hair samples were washed with solutions $0.1 \mathrm{M} \mathrm{HCl}$, acetone and water [14]. The washing procedure, each hair sample was weighed directly into a conical sample tube, $25 \mathrm{~mL}$ of the washing solution was added and the tube capped. The container was shaken on a mechanical shaker for $4 \mathrm{~h}$ at $20{ }^{\circ} \mathrm{C}$. Then the supernatant was pipetted-off and kept for further analysis. The residue was treated twice, each time with $40 \mathrm{~mL}$ of deionized water, shaken for $4 \mathrm{~h}$ and the water was pipetted-off. The hair sample was ovendried at $70^{\circ} \mathrm{C}$ for $8 \mathrm{hs}$ and then digested the next day.

\section{Hair Digestion Procedures}

All washed hair samples were digested by weighing the sample directly (about $1 \mathrm{~g}$ ) into teflon bombs, and mixture of nitric and perchloric acid mixture (HNO3:HCLO4=4:1 v/v) was added. The samples were heated on a hot plate (initially at $90{ }^{\circ} \mathrm{C}$ for $120 \mathrm{~min}$ and then at $130{ }^{\circ} \mathrm{C}$ for $\left.100 \mathrm{~min}\right)$. Standard solution of each element was prepared in a mixture of $\mathrm{HNO}_{3}, \mathrm{HClO}_{4}$ and deionized water. Detections were carried out using AAS and ETAAS.

\section{Analysis of data}

The values of the metal concentrations in tail hair of the subjects were presented as arithmetic mean $\left(\mu g g^{-1}\right)$ with standard division $( \pm \mathrm{SD})$. The statistical significance of concentrations of heavy metals between different parameters was determined by ANOVA as appropriate. The level of significance was set at $\mathrm{P}<0.05$. All calculations were performed using statistical packages SPSS (VERSION 14).

\section{Results and Discussion}

Hair is a keratin-rich tissue with abundance of cysteine residues, the sulfhydryl group of which binds with divalent cations such as lead and cadmium leading to their persistence in hair for a long period [7, 13]. Table 2 shows the $\mathrm{Pb}, \mathrm{Cd}$ and $\mathrm{Al}$ concentrations in tail hair from cows $(n=227)$ reared in industrial (Tehran) and unpolluted areas (Semnan). Cows in the vicinity of Tehran had significantly $(\mathrm{P}<0.05)$ higher concentrations of $\mathrm{Pb}$ and $\mathrm{Cd}$ in tail hair than cows from the Semnan. Cows reared around industrial urban had higher Al levels than control animals $(0.37 \pm 0.01 \mathrm{mg} / \mathrm{mL})$. However, $\mathrm{Al}$ concentrations in tail hair samples from Tehran did not differ significantly from cows reared in Semnan.

Table 2. $\mathrm{Pb}, \mathrm{Cd}$ and $\mathrm{Al}$ residues in hair $(\mathrm{mg} / \mathrm{g})$ in cattle reared around industrial and unpolluted areas

\begin{tabular}{|l|c|c|c|}
\hline Area/Elements & $\mathrm{Pb}$ & $\mathrm{Cd}$ & $\mathrm{Al}$ \\
\hline Tehran $(\mathrm{n}=165)$ & $13.09 \pm$ & $3.45 \pm$ & $0.41 \pm$ \\
& 0.91 & 0.38 & 0.02 \\
\hline Semnan $(\mathrm{n}=62)$ & $6.98 \pm$ & $2.78 \pm$ & $0.37 \pm$ \\
& 0.54 & 0.12 & 0.01 \\
\hline
\end{tabular}

The values are expressed as mean \pm SE. Values with different superscripts between rows in a column vary Significantly at $(\mathrm{P}<0: 05)$. Values in parentheses indicate ranges.

Fig. 1 shows a scatter plot of continuous data from 227 animals and quadratic regression with number of cows on the $\mathrm{x}$ axis and hair $\mathrm{Pb}$ and $\mathrm{Cd}$ in Tehran and Semnan on the $y$ axis. Cows in the Tehran had significantly higher concentrations of $\mathrm{Pb}$ and $\mathrm{Cd}$ in tail hair than cows from the Semnan. 


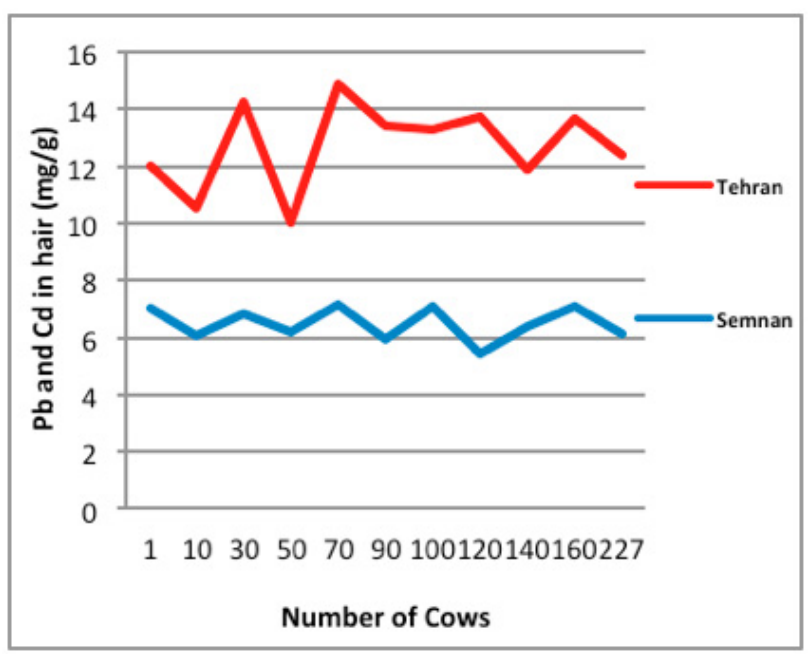

Fig. 1. Scatter plot of continuous data from 227 animals from polluted and unpolluted localities with number of cows on $\mathrm{x}$ axis and hair $\mathrm{Pb}$ and $\mathrm{Cd}(\mathrm{mg} / \mathrm{g})$ on $\mathrm{y}$ axis.

The scatter plot of continuous data on hair $\mathrm{Al}$ concentrations revealed a significant $(\mathrm{P}<0$ :05) quadratic regression between these two areas (Fig. 2). However, the hair $\mathrm{Al}$ concentration was found to be a poor indicator.

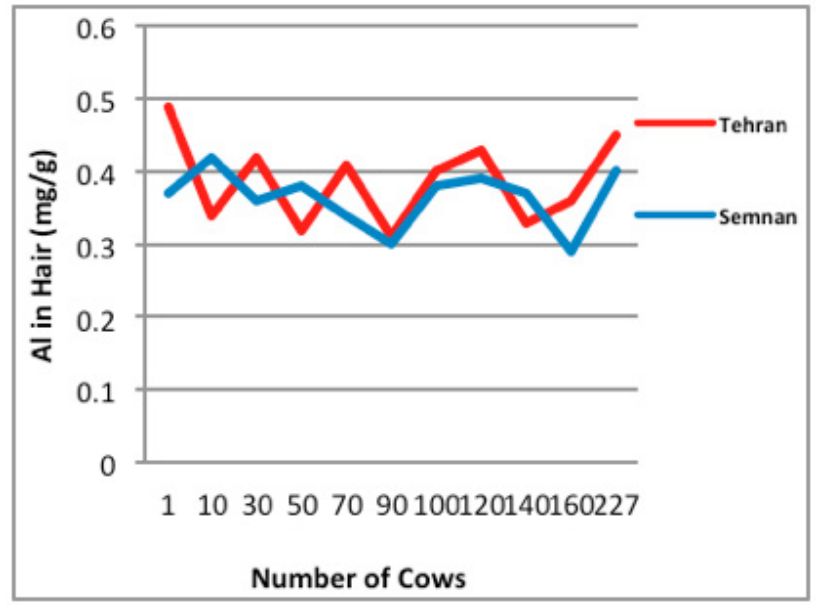

Fig. 2. Scatter plot of continuous data on hair $\mathrm{Al}(\mathrm{mg} / \mathrm{g})$ concentrations from 227 animals from polluted and unpolluted localities.

\section{Conclusion}

It is concluded that $\mathrm{Pb}$ and $\mathrm{Cd}$ accumulation in hair in the polluted area and unpolluted localities. Also strong positive correlation was between $\mathrm{Pb}$ and $\mathrm{Cd}$ concentrations from Tehran as a polluted area and Semnan as an area free from pollution. However Al concentrations in tail hair samples did not differ significantly from two areas.

\section{References}

[1] Phillips C, Gyori Z, Kovacs V. The effect of adding cadmium and lead alone or in combination to the diet of pigs on their growth, carcass composition and reproduction. J Sci Food Agric 2003; 83:135765 .

[2] Ozmen O, Mor F. Acute lead intoxication in cattle housed in an old battery factory. Vet Hum Toxicol 2004;46:255-6.

[3] Dwivedi, S.K., Swarup, D., Dey, S., Patra, R.C., 2001. Lead poisoning in cattle and buffalo near primary lead-zinc smelter in India. Vet. Hum. Toxicol. 43, 74-75.

[4] Sharma RP, Street JC. Public health aspects of toxic heavy metals in animals feeds. J Am Vet Med Assoc 1980;177:149-53.

[5] Quig, D., 1998. Cysteine metabolism and metal toxicity. Altern. Med. Rev. 3, 262-269.

[6] Vahter, M., Marafante, E., 1983. Intracellular distribution and metabolic fate of arsenite and arsenate in mice and rabbits. Chem. Biol. Interact. 47, 29-44.

[7] Raab, A., Hansen, H.R., Zhuang, L.Y., Feldmann, J., 2002. Arsenic accumulation and speciation analysis in wool from sheep exposed to arsenosugars. Talanta 58, 167-176.

[8] Rao K. Sreenivasa, T. Balaji, Rao T. Prasada, Spectrochim. Acta, 57 (2002) 1333-1338.

[9] V. A. Batzevich,1995. Science Total Environ. 164 (1995) 89-94.

[10] A. Chatt, S.A. Katz, Hair Analysis. VCH, Weinheim/New York (1988).

[11] Struempler, R.E., Larson, G.E., Rimland, B., 1985. Hair mineral analysis and disruptive behaviour in clinically normal young men. J. Learn. Disabil. 18, 609-612.

[12] Wecker, L., Miller, S.B., Cochran, S.R., Dugger, D.L., Johnson, W.D., 1985. Trace elements concentrations in hair from autisitic children. J. Mental Def. Res. 29, 15-22.

[13] Hasan, M.Y., Kosanovic, M., Fahim, M.A., Adem, A., Petroianu, G., 2004. Trace metal profiles in hair samples from children in urban and rural region of the United Arab Emirates. Vet. Hum. Toxicol. 46, 119-121.

[14] Tadayon F., Saber Tehrani M., 2009. .Endogenous and exogenous elemental speciation in human hair by various washing procedures and determination by flam and electrothermal atomic absorption spectrometry. Asian J Chem. 21, 3660-3670. 